\title{
The Impact of Authoritarian Leadership on Work-to-Family Conflict
}

\author{
Lin Qiu \\ School of Business Administration, South China University of Technology, Guangzhou 510640, China \\ Email: linqiu@scut.edu.cn
}

\begin{abstract}
To enhance the understanding of leadership influences on employee work-family conflict, this study focused on traditional Chinese leadership (i.e., authoritarian leadership). The present study investigates the impact of authoritarian leadership on employee work-to-family conflict (WFC) by focusing on the mediating role of job overload. The results from a survey of 133 working adults in China provide support for the hypotheses, indicating that authoritarian leadership is positively related to WFC; this relationship is also partially mediated by job overload. The theoretical and managerial implications of these findings are discussed.
\end{abstract}

Keywords: Authoritarian leadership, work-to-family conflict, job overload

\section{INTRODUCTION}

In the past few decades, a considerable amount of research on work-family conflict has been spurred by the increasing challenge for working adults to juggle the competing demands of work and family. Work-family conflict has been linked to some negative individual and organizational outcomes, such as withdrawal from work responsibilities, increased stress, absenteeism, low job commitment and productivity [1].

Researchers have been interested in exploring the determinants of work-family conflict. Much research has examined the impact of organization-centered policies and programs (e.g., flexible work arrangement), yet the findings so far are mixed [2]. Given that leaders act as gatekeepers for the availability and the effective implementation of work-family initiatives [3], researchers are increasingly turning their attention to how leaders' behaviors affect employees' work-family inflict. However, extant research has predominantly studied the effects of family supportive supervisor behaviour (FSSB), little is known about the potential effects of authoritarian leadership, a traditional Chinese leadership defined as a leader's asserting absolute authority and control over followers [4].

This study aims to investigate the direct effect of authoritarian leadership on work-family inflict, and the mediating effect of job overload as well. A better understanding of the effect of authoritarian leadership on employee work-family conflict is both theoretically important to enriching insights on the leader influence process, and practically relevant for managing work-family relationship through leadership change program.

\section{LITERATURE REVIEW AND HYPOTHESIS}

\subsection{Work-Family Conflict}

Based on the role theory which postulates that participation in one role will make it more difficult for individuals to participate in the other role due to the limited personal resources of time and energy, work-family conflict is commonly defined by Greenhaus and Beutell as a type of inter-role conflict in which the demands of work and family roles are incompatible in some respect so that participation in one role is more difficult because of participation in the other role [5]. The authors describe three forms of conflict: time-based, strain-based, or behavior-based. Time-based conflict occurs when time spent in one role interferes with one's ability to fulfill expectations in the other role. Strainbased conflict occurs when psychological strain created by one role interferes with the ability to carry out the demands of the other role. Behavior-based conflict occurs when behavior required in one role is incompatible with the expectations of the other role.

In addition, work-family conflict is a bidirectional construct, directionality, that is, work-to-family conflict (WFC) and family-to-work conflict (FWC). Both WFC and FWC are negatively associated with a series of desirable work, family, and health-related outcomes, such as job satisfaction, organizational commitment, family satisfaction, and psychological well-being [1]. This study focus on WFC, because research has revealed that the antecedents of work-family conflict are domain-specific, that is, work domain variables influence WFC and family domain variables influence FWC [1]. 


\subsection{Authoritarian leadership and WFC}

As a style of leadership which has long been rooted in the Chinese traditional culture, paternalistic leadership is defined as a style of leadership characterized by high discipline and authoritarianism, fatherly benevolence and high moral standards [4]. Paternalistic leadership contains three essential components, that is, authoritarianism, benevolence, and moral leadership. Researchers has confirmed that each component demonstrated different leadership styles, therefore, the three components should be studied separately [6].

In the traditional Chinese culture, families are patriarchal, and everyone must listen and obeyed to the father. The process of inferring the style of leadership from families to organizations was called as Pan-Familism [7]. That is, the leader may analogize the family relationship to the enterprise by treating the members of the enterprise as family. The leader may bring the family values and behaviors into the organization such as demonstrating paternal authority, treating subordinates as children. The asymmetrical power between the leader and the subordinate would easily result in an authoritarian leadership style [8]. Thus, this study focuses on authoritarian leadership, referring to the incontestability of the authority of the leader, whereby subordinates were subjected to strict control and subordination to the leader without reservation. The conservation of resources theory (COR) suggests that individuals strive to obtain, maintain, and invest resources [9]. When individuals are subjected to actual and/or threat of resource loss, they experience psychological, physical, and behavioural strains. Given that authoritarian leaders exert absolute power and control over their subordinates and requires absolute obedience from them [4], authoritarian leadership has normally been viewed among scholars and practitioners as a dysfunctional leadership style. The extant literature shows that authoritarian leadership is negatively related to many desirable employee outcomes, such as organizational commitment, job performance, and intention to stay [10], it can be conceptualised as a workplace stressor. It has been argued that authoritarian behaviors are likely to induce fear in employees, and may make them feel uneasy or oppressed [11]. According to Greenhaus and Beutell [5], WFC occurs when psychological strain created by work role interferes with the ability to carry out the demands of the family role. Thus, employees exposed to authoritarian leadership are likely to perceive resource insufficiency and/or the threat of not gaining resources, resulting in experiencing various WFC.

Hypothesis 1. Authoritarian leadership will be positively related to subordinates' WFC.

\subsection{Authoritarian leadership and Overload}

Since an authoritarian leader emphasizes absolute authority and control over the subordinates, and punishes subordinates when they do not follow his or her rules [12].
Employees may be afraid that disobedience may result in authoritarian leaders' retaliation and poor performance rating. In addition, authoritarian leaders demand that subordinates perform tasks according to their requirements strictly and give them no discretion to solve work-related problems, Meanwhile, employees may choose to accept their job arrangements even when they feel they are too much for them or beyond their abilities. Thus, it follows that when an employee encounters an authoritarian leader, he or she will be subject to job overload.

Hypothesis 2. Authoritarian leadership will be positively related to subordinates' job overload.

\subsection{Overload as a Mediator}

In their seminal work, Greenhaus and Beutell hypothesized that exposure to domain (work/family) stressors may lead to irritability, fatigue, or preoccupation, which might limit one's performance in the other domain (family/work) [5]. WFC is characterized by a process in which the demands of work role make performance of the family role more difficult. A meta-analytic review shows that role overload are the primary determinants of work-family conflict [13]. Thus, this study argues that job overload leads to WFC to the extent that individuals bring their work home, or cannot stop thinking about work subtracting time and energies from activities with their families.

Hypothesis 3. Job overload will be positively related to employees' WFC.

As previously argued, employees who experience higher level of authoritarian leadership might be assigned too much work that will not only take more time to complete, but also drain employees' mental resources when completing it [9]. This additional cost of time and mental resources may make it difficult for employees to fulfil family responsibilities, and thus might lead to increased WFC. Therefore, based on the aforementioned argument and the earlier discussion on the direct relationships between authoritarian leadership and job overload, we believe that job overload will mediate the relationship between authoritarian leadership and WFC.

Hypothesis 4. Job overload will mediate the positive relation between authoritarian leadership and WFC.

\section{METHODS}

\subsection{Participants}

The participants in this study were full-time employees in China. In all, $133(65.5 \%)$ participants completed all sections of the survey. Out of these participants, $65.4 \%$ are female, with the majority $(63.9 \%)$ being unmarried. Approximately $98.5 \%$ were 40 years old or less, $45.9 \%$ had at least one kid. 


\subsection{Measurement}

All the measurements were rated on a 5-point scale that ranged from 1 (strongly disagree) to $5=$ (strongly agree). Authoritarian leadership was measured using the 4-item scale developed by Cheng \& Wang [8]. In the present study, Cronbach's $\alpha$ for authoritarian leadership was 0.85 .

Work-to-family conflict (WFC) was measured using the 4item scale developed by Wayne, Musisca, \& Fleeson [14]. In the present study, Cronbach's $\alpha$ for WFC was .84 .

$J o b$ overload was measured using the 3 -item scale developed by Bolino \& Turnley [15]. In the present study, Cronbach's $\alpha$ was .83 .

According to previous research, this study statistically controlled for gender $(0=$ female, $1=$ male $)$, age $(1=21$ or less, $2=21-30,3=31-40,4=41-50,5=51$ or more), position ( 1 = non-supervisory, 2 = first-level supervisor, $3=$ middle-level manager, 4 = top-level manager), marital status $(1=$ single, $2=$ married), and number of children in all analyses to rule out alternative explanations for our findings.

\section{RESULTS}

\subsection{Descriptive Statistics and Correlational Analyses}

Table 1 shows the means, standard deviations, and intercorrelations of all study variables. The patterns of correlations are consistent with both theory and previous research. Authoritarian leadership was positively related to job overload and WFC. Furthermore, WFC was positively related to job overload.

\subsection{Hypothesis Testing}

This study used hierarchical multiple regressions to test Hypotheses $1-3$. In all analyses, we entered the control variables of gender, age, position, marital status, and number of children first into the regression model, and then the primary study variables. Table 2 shows the regression results for estimated coefficients of the mediation model.

Table 1 Descriptive statistics and correlational analyses

\begin{tabular}{|l|c|c|c|c|c|c|c|c|}
\hline & $\mathbf{1}$ & $\mathbf{2}$ & $\mathbf{3}$ & $\mathbf{4}$ & $\mathbf{5}$ & $\mathbf{6}$ & $\mathbf{7}$ & $\mathbf{8}$ \\
\hline 1. Gender & 1.00 & & & & & & & \\
\hline 2. Age & $.17^{*}$ & 1.00 & & & & & & \\
\hline 3. Position & $.18^{*}$ & $.54^{* *}$ & 1.00 & & & & & \\
\hline 4. Marital status & .08 & $.45^{* *}$ & $.35^{* *}$ & 1.00 & & & & \\
\hline 5. Number of Kids & $.19^{*}$ & $.56^{* *}$ & $.45^{* *}$ & $.56^{* *}$ & 1.00 & & & \\
\hline $\begin{array}{l}\text { 6. Authoritarian } \\
\text { leadership }\end{array}$ & $.17^{*}$ & -.11 & -.03 & .10 & .01 & 1.00 & & \\
\hline 7. Overload & -.04 & -.01 & -.09 & -.13 & .04 & $.19^{*}$ & 1.00 & \\
\hline 8. WFC & .09 & .02 & -.05 & -.06 & -.04 & $.36^{* * *}$ & $.59^{* * *}$ & 1.00 \\
\hline Mean & .35 & 2.40 & 2.19 & 1.66 & .62 & 3.55 & 3.18 & 3.30 \\
\hline SD & .48 & .71 & .92 & .52 & .78 & 1.02 & .93 & .85 \\
\hline
\end{tabular}

${ }^{*} \mathrm{p}<.05 ;{ }^{* *} \mathrm{p}<.01$

Baron and Kenny [16] proposed a four-step approach to establish the conditions for mediation. As can be seen in Table 2, after controlling for several demographic variables, authoritarian leadership was significantly related to job overload (Model 2; $\beta=.24, \mathrm{p}<.01$ ). Thus, Condition (a) for the mediation effect was met. WFC was also significantly related to authoritarian leadership (Model 4; $\beta$ $=.38, \mathrm{p}<.001$ ), satisfying Condition (b). WFC was positively related to job overload (Model $5 ; \beta=.55, \mathrm{p}<.01$ ). Thus, Condition (c) was met. Further, after job overload was taken into account, the effect of authoritarian leadership on WFC became weaker, albeit still significant (Model 5; $\beta=$ $.25, \mathrm{p}<.01$ ), which suggests a partial mediation. Thus, Condition (d) was satisfied. To provide a more rigorous test of the mediation effect, we used Preacher and Hayes's [17] macro to test the indirect effect with 5,000 bootstrap samples. Results showed that the $95 \%$ confidence interval of the indirect effect estimate $[.03, .19]$ did not contain zero, indicating that the indirect effect was significant. Taken together, Hypotheses 1-4 were supported, that is, job overload partially mediated the relationship between authoritarian leadership and WFC.

\section{DISCUSSION}

This study explored the relationship between authoritarian leadership and WFC, and the results showed that authoritarian leadership has a positive effect on employees' job overload and a positive indirect effect on the experience of WFC through job overload. The findings of this study make several important contributions to the literature. 
First, this study contributes to the theoretical research on authoritarian leadership by exploring the effects of authoritarian leadership on employee work-family experience. According to scholars [4], supervisors have a crucial influence of the experiences of their subordinates. However, existing research has largely ignored the link between leadership and employee work-family outcomes [18]. Particularly, no study to date had linked empirically authoritarian leadership to work-family interface. This study filled this gap by assessing the effects of authoritarian leadership on work-to-family conflict.

Table 2 Results of the hierarchical regression analysis

\begin{tabular}{|c|c|c|c|c|c|}
\hline & \multicolumn{2}{|c|}{ Job Overload } & \multicolumn{3}{|c|}{ WFC } \\
\hline & M 1 & M 2 & M 3 & M 4 & M 5 \\
\hline Gender & -.05 & -.09 & .10 & .03 & .08 \\
\hline Age & .06 & .11 & .10 & .18 & .12 \\
\hline Position & -.13 & -.12 & -.08 & -.07 & .00 \\
\hline Marital Status & $-.21^{*}$ & $-.26^{* *}$ & .06 & -.13 & .01 \\
\hline Number of Kids & .19 & .19 & -.05 & -.04 & -.15 \\
\hline Authoritarian leadership & & $.24^{* *}$ & & $.38^{* * *}$ & $.25^{* *}$ \\
\hline Job Overload & & & & & $.55^{* * *}$ \\
\hline$\Delta \mathrm{R}^{2}$ & .05 & $.05^{*}$ & .02 & $.14^{* * *}$ & $.28^{* * * *}$ \\
\hline $\mathrm{F}$ & 1.24 & $2.29^{*}$ & .54 & $3.93^{* * *}$ & $13.76^{* * * *}$ \\
\hline
\end{tabular}

$* \mathrm{p}<.05 ; * * \mathrm{p}<.01$. All coefficients reported are standardized betas.

Second, this study echoed the call of Li et al. [18] to adapting other theoretical perspectives that may shed light on the role of leader behavior in relation to employee workfamily outcomes by applying COR theory to explain how authoritarian leadership in the workplace influenced employees' perception of WFC. Based on the COR theory [9], authoritarian leadership can be considered a workplace stressor that not only reduces the necessary resources employees need to complete their work, but also creates stressful environments that will further increase job demands, and thus intensifies employee WFC. To our knowledge, this is only empirical study to examine the potential negative effects of passive leadership on workfamily conflict. Results of this study further support the notion that authoritarian leadership is an ineffective leadership style in contemporary organizations. In addition, the results from the current study may encourage future researchers to address the impact of authoritarian leadership on employee family functions.

In addition to the theoretical contributions mentioned above, this research yields several practical implications. As work and family represent the two most important roles for working adults, and the incompatibility between the two life roles have detrimental effects on both individuals and organizations [1], the findings of this study suggests that authoritarian leadership should draw more attention as a disruptor to employee well-being and organization performance. Thus, organizations should devote more effort to decrease authoritarian leader behaviors among managers at different levels through targeted leadership development programs. Meanwhile, authoritarian leadership style should also be paid close attention during recruitment and promotion processes.

\section{CONCLUSION}

This study represents an important step toward better understanding how authoritarian leadership may link to employee work-family conflict. Specifically, when employees believe that they are working with an authoritarian leader, they are more likely to feel a sense of job overload, which in turn, enhance their experience of WFC. Therefore, organizations should be aware that preventing authoritarian supervision may improve the immediate workload experiences, and help employees effectively manage the family-work interface.

\section{ACKNOWLEDGMENT}

This work was supported by the National Social Science Fund of China (18BSH115).

\section{REFERENCES}

[1] F.T. Amstad, L.L. Meier, U. Fasel, et al., A metaanalysis of work-family conflict and various outcomes with a special emphasis on cross-domain versus matching-domain relations, J. Occup. Health Psych. 16 (2011) 151-169. DOI: https://doi.org/10.1037/a0022170 
[2] E.E. Kossek, B.A. Lautsch, Work-family boundary management styles in organizations: a cross-level model, Organ. Psychol. Rev. 2 (2012) 152-71. https://doi.org/10.1177/2041386611436264

[3] C. Straub, Antecedents and organizational consequences of family supportive supervisor behavior: A multilevel conceptual framework for research, Hum. Resour. Manag. Rev. 22 (2012) 15-26. https://doi.org/10.1016/j.hrmr.2011.08.001

[4] J.L. Farh, B.S. Cheng, A cultural analysis of paternalistic leadership in Chinese Organizations: Management and organizations in the Chinese context, London: Palgrave Macmillan, 2000.

[5] J.H. Greenhaus, N.J. Beutell, Sources of conflict between work and family roles, Acad. Manag. Rev. 10 (1985) 76-88. https://doi.org/10.31979/etd.2x82-58pg

[6] C.C. Chen, J.L. Farh, Developments in understanding Chinese leadership: Paternalism and its elaborations, moderations, and alternatives, in M. Bond (Eds.), Handbook of Chinese Psychology, New York, NY: Oxford University Press, 2010, pp. 599-622. DOI: http://dx.doi.org/10.1093/oxfordhb/9780199541850.013 .0036

[7] K.S. Yang, Social orientation of the Chinese: Perspective on social interactions, in K.S. Yang, A.B. Yu (Eds.), Chinese psychology and behavior: Conceptions and methods, Taipei: Laureat, 1993, pp. 87-142.

[8] M-Y Cheng, L. Wang, The Mediating Effect of Ethical Climate on the Relationship between Paternalistic Leadership and Team Identification: A Team-Level Analysis in the Chinese Context, J. Bus. Ethics. $\quad 129 \quad$ (2015) 639-654. https://doi.org/10.1007/s10551-014-2189-5

[9] S.E. Hobfoll, Conservation of resources: A new attempt at conceptualizing stress, Amer. Psychologist. 44 (1989) 513-524. https://doi.org/10.1037/0003066x.44.3.513

[10] J.M. Schaubroeck, Y. Shen, S. Chong, A dual-stage moderated mediation model linking authoritarian leadership to follower outcomes, J. Appl. Psych. 102 (2) (2017) 203-214. http://dx.doi.org/10.1037/ap10000165

[12] M. Wu, X. Huang, C. Li, et al., Perceived interactional justice and trust-in-supervisor as mediators for paternalistic leadership, Manag. Organ. Rev. 8 (1) (2012) 97-121. https://doi.org/10.1111/j.17408784.2011.00283.x
[11] S.C.H. Chan, X. Huang, E. Snape, C.K. Lam, The Janus face of paternalistic leaders: Authoritarianism, benevolence, subordinates' organization- based selfesteem, and performance, J. Organ. Behav. 34 (2013) 108-128. http://dx.doi.org/10.1002/job.1797

[13] J.S. Michel, L.M. Kotrba, J.K. Mitchelson, et al., Antecedents of work-family conflict: A meta-analytic review. J. Organ. Behav. 32 (2011) 689-725. https://doi.org/10.1002/job.695

[14] J.H. Wayne, N.Musisca, W. Fleeson, Considering the role of personality in the work-family experience: Relationships of the big five to work-family conflict and facilitation, J. Vocat. Behav. 64 (1) (2004) 108-130. https://doi.org/10.1016/s0001-8791(03)00035-6

[15] M.C. Bolino, W.H. Turnley, The personal costs of citizenship behavior: The relationship between individual initiative and role overload, job stress, and work-family conflict. J. Appl. Psych. 90 (4) (2005) 740 748. https://doi.org/10.1037/0021-9010.90.4.740

[16] R.M. Baron, D.A. Kenny, The moderator-mediator variable distinction in social psychological research: Conceptual, strategic and statistical considerations, J. Pers. Soc. Psychol. 51 (1986) 1173-1182. https://doi.org/10.1037/0022-3514.51.6.1173

[17] K.J. Preacher, A.F. Hayes, SPSS and SAS procedures for estimating indirect effects in simple mediation models, Behavior Research Methods, 36 (2004) 717-731. https://doi.org/10.3758/bf03206553

[18] A. Li, K.D. McCauley, J.A. Shaffer, The influence of leadership behavior on employee work-family outcomes: A review and research agenda, Hum. Resour. Manag. Rev. $27 \quad$ (2017) 458-472. https://doi.org/10.1016/j.hrmr.2017.02.003 